NBER WORKING PAPER SERIES

\title{
THE PERMANENT EFFECTS OF FISCAL CONSOLIDATIONS
}

\author{
Antonio Fatás \\ Lawrence H. Summers \\ Working Paper 22374 \\ http://www.nber.org/papers/w22374 \\ NATIONAL BUREAU OF ECONOMIC RESEARCH \\ 1050 Massachusetts Avenue \\ Cambridge, MA 02138 \\ June 2016
}

We would like to thank the IMF research department for making available the data on 5-year forecasts for older vintages of the IMF World Economic Outlook. The views expressed herein are those of the authors and do not necessarily reflect the views of the National Bureau of Economic Research.

NBER working papers are circulated for discussion and comment purposes. They have not been peer-reviewed or been subject to the review by the NBER Board of Directors that accompanies official NBER publications.

(C) 2016 by Antonio Fatás and Lawrence H. Summers. All rights reserved. Short sections of text, not to exceed two paragraphs, may be quoted without explicit permission provided that full credit, including $(\subset$ notice, is given to the source. 
The Permanent Effects of Fiscal Consolidations

Antonio Fatás and Lawrence H. Summers

NBER Working Paper No. 22374

June 2016, Revised August 2016

JEL No. E32,E62,O4

\begin{abstract}
$\underline{\text { ABSTRACT }}$
The global financial crisis has permanently lowered the path of GDP in all advanced economies. At the same time, and in response to rising government debt levels, many of these countries have been engaging in fiscal consolidations that have had a negative impact on growth rates. We empirically explore the connections between these two facts by extending to longer horizons the methodology of Blanchard and Leigh (2013) regarding fiscal policy multipliers. Our results provide support for the presence of strong hysteresis effects of fiscal policy. The large size of the effects points in the direction of self-defeating fiscal consolidations as suggested by DeLong and Summers (2012). Attempts to reduce debt via fiscal consolidations have very likely resulted in a higher debt to GDP ratio through their long-term negative impact on output.
\end{abstract}

\author{
Antonio Fatás \\ INSEAD \\ 1 Ayer Rajah Avenue \\ 138676 Singapore \\ Singapore \\ antonio.fatas@insead.edu \\ Lawrence H. Summers \\ Harvard Kennedy School of Government \\ 79 JFK Street \\ Cambridge, MA 02138 \\ and NBER \\ lhs@harvard.edu
}




\section{Introduction.}

After more than eight years since the global financial crisis started, most advanced economies are still suffering from its aftermath and GDP remains far from its pre-crisis trend. Relative to previous business cycles, the current cycle can be characterized by a much more protracted and persistent recession without a strong recovery that has allowed for a return to trend.

While this persistence is now recognized by policy makers, it was not obvious in the early years of the crisis. When the crisis started, the original GDP forecasts suggested a progressive return towards previous trends, as it would be expected from a standard recovery phase. But that return never happened, and GDP forecasts were continuously revised downwards as the crisis unfolded leading to a succession of positively correlated forecast errors. As time passed, pessimism grew about the potential level of GDP. ${ }^{1}$

While this phenomenon is true for most advanced economies, including the US, the pattern has been the most dramatic for the European economies, where the crisis has been felt the most.

In Figure 1 we show the evolution of US GDP as predicted by the IMF World Economic Outlook (WEO) three different dates: April 2007 (before the crisis), April 2008 (after the first wave of the crisis) and April 2010 after most of the effects of the crisis were settled (at least for the US). We can see how the downward revisions of GDP that took place in 2008 were followed by additional revisions in 2010 as the crisis was much more persistent than expected. ${ }^{2}$

We can also see from the forecasts that in 2010 the deviations from previous trends were expected to be persistent. And this pessimism was not unfounded as the 2010 forecast for GDP in 2015 ended up being very much in line with the actual data for that year. Today, there is very little hope of returning anywhere close to the pre-crisis GDP trend.

\footnotetext{
1 See Ball (2014).

2 Each WEO provides forecasts for the next five years. We have extended these forecasts by extrapolating average growth rates from 2000 until the last year in which a forecast is included. For example, for the WEO 2010 we have forecasts up to 2015. We extend them to 2021 by using the average growth rate between 2000 and 2015.
} 
Figure 1. US GDP

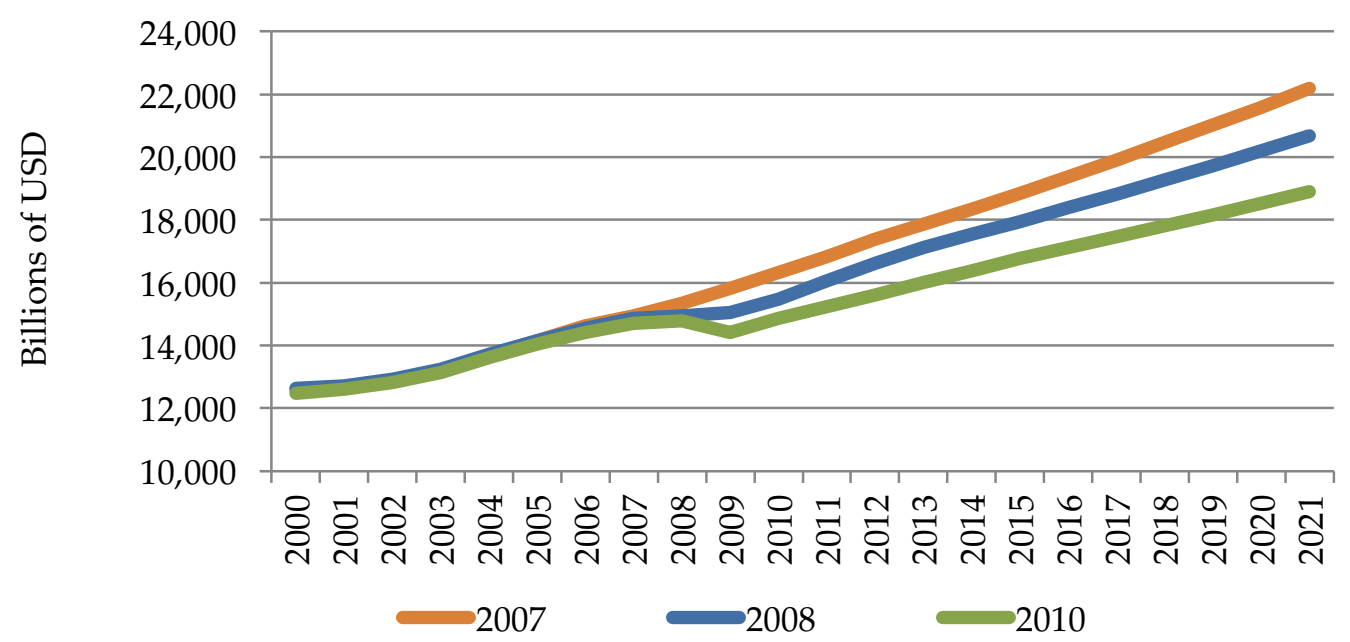

Figure 2. Revisions to Euro GDP and Potential Trend

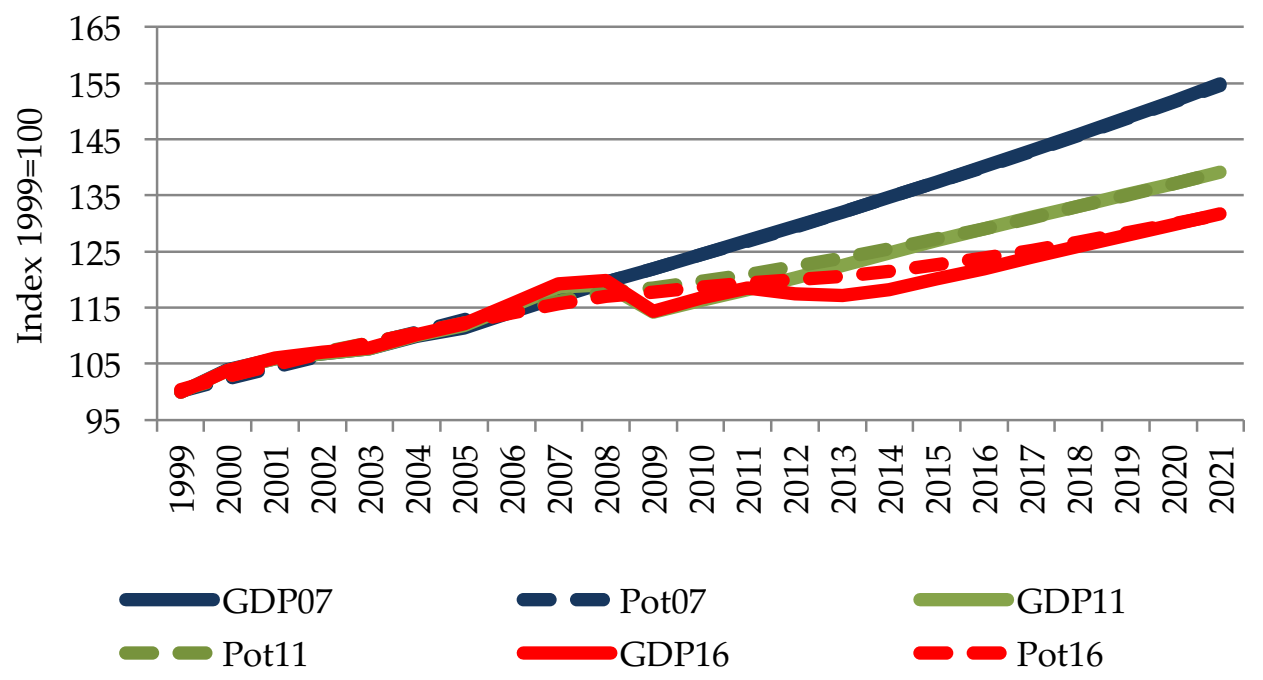

In the case of Europe, the same phenomenon looks even more dramatic. Not only the revisions were large in the first years but they continued even after 2010 as the Euro zone entered its second recession. And when forecasts were being revised downwards, they also did so for long horizons. In Figure 2 we show the change in both GDP as well as estimates of potential output for the Euro area in three different dates: April 2007 (before the crisis), April 2011 (after the first wave of the crisis) and April 2016, the latest available data. ${ }^{3}$

3 The April 2007 WEO does not contain forecast beyond 2008 for GDP or Potential. In that case, we are we are extrapolating both series using the average growth rate since 1999. The April 2011 
What is clear from the chart is that the current crisis is very persistent. Relative to the trend that the Euro area was following since the Euro was launched in 1999, GDP today is still far below that level (about 13\% below). In addition, potential has been revised downwards by a similar amount. The IMF expects today that by 2021 the Euro area will be about 15\% below the level implied by its pre-crisis trend. ${ }^{4}$ The revisions to potential output have gone hand in hand with the change in output. By 2011 both output and potential had fallen relative to 2007 projections. By 2015 as output remains far below the 2011 projections, potential output has also been revised downwards and by a similar magnitude.

In some ways the persistence of GDP during the crisis does not entirely come as a surprise. The fact that recessions are persistent and can even leave permanent effects on GDP trend is well known in the academic literature since the presence of unit roots in GDP became accepted. There is also more specific evidence about the length and persistence of crises with a strong financial component, as the one we have just witnessed.

However, there is no consensus on the origin of this persistence and how it should affect economic policy discussions. Some see it as a reflection of structural issues and the need for reforms. Others see it as the permanent effects of cyclical phenomena that might have been exacerbated by poor economic policy choices. In this second case, the wrong economic policy can be partly to blame for the permanent loss in output.

The debate is particularly relevant for the current crisis. Many advanced economies have been dealing with the consequences of large fiscal deficits and debt that required a process of fiscal consolidation. In order to decide on the necessary amount of fiscal consolidation, policy makers needed to incorporate their views on GDP and its future growth rate to assess debt sustainability. As fiscal consolidation was implemented, we witnessed its negative effects on output growth. If multipliers are large, this can lead to a negative loop in which negative GDP growth leads policy makers to believe that further fiscal policy adjustments are needed.

WEO contains forecasts up to 2016. We are extrapolating both series for the next five years using the average growth rate since 1999. The April 2016 WEO contains forecasts up to 2021 for both variables. GDP data prior to 2007 is not identical in all three vintages because of data revisions. Potential was also revised backwards for several of these years.

${ }^{4}$ These numbers underestimate the actual changes in potential because the IMF has revised backwards its estimates for potential for earlier years. In our empirical analysis we will correct for these effects and we explain our methodology in an appendix at the end of the paper. 
In order to avoid this potential negative loop, policy makers look at measures of sustainability that are based on long-run projections of GDP to avoid the pessimistic bias introduced by using current low growth rates. For this reason, it is common practice for debt ratios to be calculated as a \% of potential GDP. But as shown in Figure 2, potential GDP measures were also changing as a result of the crisis in a way that was not too different from GDP. What if potential output was also being affected by the crisis itself? And what if fiscal policy, through its cyclical effects, was partly responsible for the reduction in potential GDP? Ignoring these effects would make fiscal policy unnecessarily contractionary. This is the focus of our paper. By extending the methodology of Blanchard and Leigh (2013) to longer horizons as well as applying it to potential output we analyze how fiscal consolidations during the 2009-2011 period led to changes in our long-term views on GDP and how this potentially created negative permanent effects on GDP.

We make use of IMF forecasts of both actual and potential GDP and analyze how they changed in responses to fiscal consolidations plans implemented in the early years of the crisis (2009-2011). The results suggest a strong correlation between fiscal consolidations and revisions to long-term and potential GDP. We show that fiscal policy had a negative impact on output that extends over a long horizon, as the long-term performance of GDP and the estimates of potential output were both negatively affected by fiscal consolidations.

The size of the effect is very large. In fact, our estimates provides evidence supporting the argument of DeLong and Summers (2012) who bring up the possibility of self-defeating fiscal consolidations, i.e. reductions in deficits that end up delivering higher debt-to-GDP ratios because of their negative effects on potential GDP. This has strong implications for the assessment of economic policies during the crisis. The cost of austerity extends beyond a short-run impact on GDP, it permanently affects the expected path of GDP and its effects on sustainability are exactly the opposite than its original goals.

The paper is organized as follows. Section 2 presents an analysis of the persistence of GDP during the crisis. Section 3 compares this persistence to the behavior of potential output. Section 4 discusses alternative theoretical explanations for this behavior. Section 5 uses the fiscal consolidation of 2009-2011 as a way to identify the causes of persistence. Section 6 compares our estimates to the parameters of DeLong and Summers (2012) and Section 7 concludes. 


\section{The persistence of the Global Financial Crisis.}

\subsection{Forecast errors and persistence.}

Starting in early 2007 GDP growth in advanced economies slowed down. By the end of 2007 the decrease in growth rates was evident and it materialized in a recession that started in 2008 and deepened in 2009. ${ }^{5}$ The crisis came as a surprise to forecasters, both private and official.

To understand how far forecasts were from the actual values of GDP we make use in our analysis of the forecasts made by the World Economic Outlook (WEO). The WEO is produced every 6 months, in April and October. The IMF makes its forecasts available through an online database that includes forecasts for at least two years. But there is also an unpublished complete set of 5-year forecasts to which we had access and that we use in our empirical analysis.

We start with the April 2007 issue of the WEO that, to a large extent, precedes the crisis. We take the 2006 data in that vintage of the database as factual and ignore the fact that later issues of the WEO will revise the data. We make use of the available forecasts going all the way to the year 2012.

We use the following notation for the forecast made in year $t$ of a variable $Y$ for the year $t+i$.

$$
Y_{t+i}^{F, t}
$$

So for GDP in 2009, the forecast made in 2007 will be expressed as

$$
G D P_{2009}^{F, 2007}
$$

We compare these forecasts with the actual data for GDP. The data comes from the April 2016 edition of the WEO. We can for example calculate the forecast error for the year 2009 as:

$$
F E_{G D P, 2009}^{2007}=\frac{G D P_{2009}-G D P_{2009}^{F, 2007}}{G D P_{2009}^{F, 2007}}
$$

5 The NBER declared December 2007 as the starting month for the US recession. The CEPR concluded that the Euro had entered a recession in the first quarter of 2008. 
Because of data revisions, changes in base year and also changes in national accounting rules, the forecast and the actual data might not be comparable as they might not be in the same units or follow the same national accounting criteria. ${ }^{6}$ Because we are interested in revisions to growth rates, we will make the two number comparable by rebasing the original WEO 2007 real GDP series and its forecasts so that the 2006 data matches the data for that year of the WEO April 2016. Given that the 2006 data now coincides in both the April 2007 and the April 2016 databases, the expression above can be simply calculated as the forecast error of accumulated GDP growth from 2006 to 2009. ${ }^{7}$

We first plot the data for 34 advanced economies (Figure 3). ${ }^{8}$ The forecast of real GDP for the year 2009 was clearly too optimistic compared to the actual data. And for some countries such as Estonia, Latvia or Ireland the forecast error is as large as $30 \%$.

Figure 3. Forecast Error Real GDP 2009

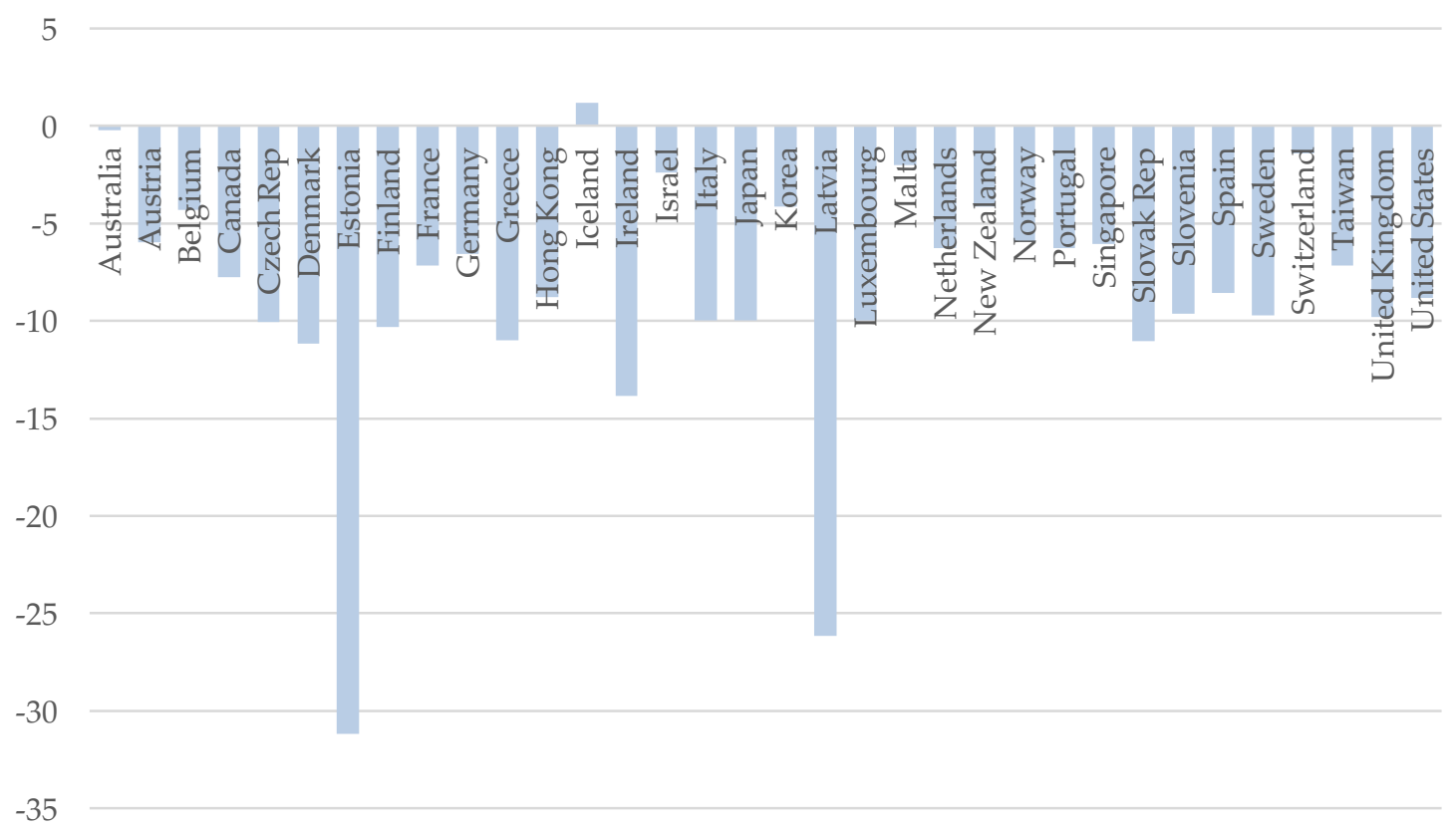

We can think of these figures as the cyclical shock that hit advanced economies in the years 2007-2009, where by cyclical shock we have in mind the unexpected change in GDP during those two years.

\footnotetext{
${ }^{6}$ Since October 2014 the WEO has started using updated data using ESA2010 criteria.

${ }^{7}$ An appendix at the end of the paper describes in detail the calculation of the forecast error.

${ }^{8}$ An appendix at the end of the paper includes the list of all countries used in our analysis.
} 
The next question is how persistent this shock was. As we move our horizon forward and as time passes, did these cyclical events became temporary deviations from trend or did we continue seeing a large forecast error? If these deviations were indeed transitory, we would expect the forecast error to decrease over time as output returns to trend.

We continue using the April 2007 WEO and look at the forecast made for 2012. We also extend the forecast horizon to 2015 by extrapolating GDP growth rates in the $2000-2012$ period. ${ }^{9}$

When we compare the three forecast errors for all advanced economies we see a very large amount of persistence. Figure 4 shows the data for a representative sample of countries. The deviations of real GDP from forecasts in 2012 is almost always larger than those in 2009. The 2015 forecast error is also typically larger than the 2012 one, in particular in the European countries. This suggests that we see very little (or none) trend reversion and that the first shock continued its propagation during the 2009-2015 years and, in that sense, it became permanent. We therefore confirm in this figure the results of Ball (2014): there is strong evidence that the 2008 crisis left permanent effects on GDP judged by the state of these economies by the year 2015 .

The fact that shocks to GDP are persistent is known since the first discussions on the existence of a unit root in GDP and are not just relevant to the last crisis. For example, Campbell and Mankiw (1989) were the first ones to look at GDP persistence in an international sample. Using simple univariate regressions, they analyzed by how much an unexpected $1 \%$ change in GDP changes future values of GDP. Their conclusion was that the initial change in GDP gets propagated over very long horizons. By comparing forecast errors at different horizons we are performing a similar exercise but for a single event over an eight-year window.

\footnotetext{
${ }_{9}^{9}$ When we extend the IMF forecasts beyond their 5 year horizons we always include the data since 2000 as well as the 5 years of forecast ahead to produce and average growth rate that is then applied to the years beyond those five. This could be considered as a pessimistic scenario as we are including the crisis years to calculate a future trend. We have reproduced all our results using only the available years (without using the forecasts) as well as just the years before the crisis (2008). Qualitatively the results are identical but forecast errors become larger if trends are calculated excluding the crisis years.
} 
Figure 4. Forecast Error Real GDP 2009, 2012 and 2015.

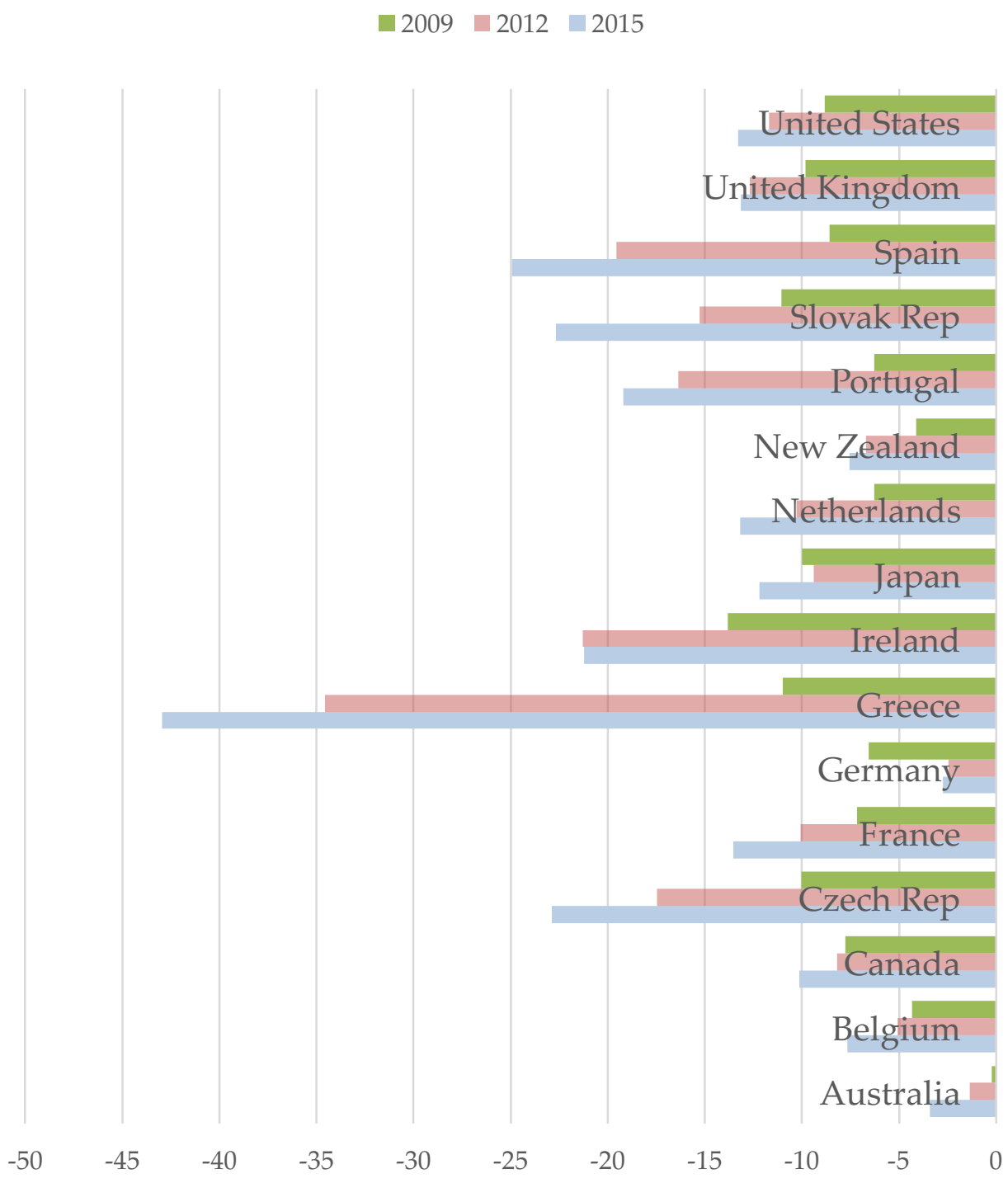

What we can also see in Figure 4 is not just that GDP was lower in 2012 or 2015 than what we expected, it is that, across countries, the deviation of GDP from its forecast in those years is very much correlated with the size of the first shock. The countries where the initial shock was large are the same countries where the forecast error several years ahead is the largest. This is an important fact because it suggests that there is a positive correlation in forecast errors across countries so the changes in GDP over long horizons are related to the size of the initial shock. This would not be the case if we were looking at random independent shocks taking place in different years. 
To make this correlation in cross-country persistence explicit we run a regression of the forecast error for these later years against the forecast error for 2009. For this analysis we also include an additional horizon by calculating the forecast error for $2021 .{ }^{10}$

In Table 1 we show the results for all advanced economies. The coefficient is greater than one, signaling that the outlook for 2012, 2015 and 2021 has changed even more than the unexpected change in GDP in 2009. In other words, what the regression shows is that these forecast errors over longer horizons are correlated with the initial change in GDP. Countries that suffer larger crisis have seen a much larger downward revision of our GDP estimates for the future, the crisis is seen as long lived.

Table 1. Persistence of Forecast Errors Real GDP. Advanced Economies.

\begin{tabular}{lccc}
\hline Advanced & \multicolumn{3}{c}{ Forecast Error Real GDP } \\
& 2012 & 2015 & 2021 \\
\hline Forecast Error & $1.086^{* * *}$ & $1.429^{* * *}$ & $1.848^{* * *}$ \\
Real GDP 2009 & $(0.123)$ & $(0.151)$ & $(0.206)$ \\
& & & \\
Constant & -2.120 & -2.202 & -2.799 \\
& $(1.340)$ & $(1.748)$ & $(2.581)$ \\
Observations & 34 & 34 & 34 \\
R-squared & 0.592 & 0.611 & 0.605 \\
\hline \multicolumn{4}{c}{ Robust standard errors in parentheses } \\
\multicolumn{4}{c}{$* * * 0.01,{ }^{* *} \mathrm{p}<0.05,{ }^{*} \mathrm{p}<0.1$}
\end{tabular}

Interestingly, a similar pattern is visible among a group of emerging markets (Table 2). Using the same methodology as above we replicate the analysis for a sample of 31 emerging markets and we get similar result with an even larger coefficient. $^{11}$

\footnotetext{
${ }^{10}$ We use 2021 because it is the latest year for which the April 2016 WEO produces a forecast. Although we refer to this figure as a forecast error, what we are really capturing is the change in forecast for the year 2021 between our extended forecast using the IMF data of the April 2007 WEO and the one produced by the IMF for the WEO in April 2016.

11 The fact that persistence is larger for emerging markets with higher growth rates is consistent with the findings of Fatás (2000).
} 
Why is output so persistent? Is the labor market relevant to explain the persistence of GDP shocks? We replicate in Table 3 the specification of Table 1 but with the addition of the forecast error of both the unemployment rate and employment over the same years to understand if changes in the labor market can help explain the persistence of GDP forecast errors in 2015 and 2021.

Table 2. Persistence of Forecast Errors Real GDP. Emerging.

\begin{tabular}{lccc}
\hline Emerging & \multicolumn{3}{c}{ Forecast Error Real GDP } \\
& 2012 & 2015 & 2021 \\
\hline \multirow{3}{*}{ Forecast Error } & $1.588^{* * *}$ & $2.180^{* * *}$ & $2.180^{* * *}$ \\
Real GDP 2009 & $(0.229)$ & $(0.391)$ & $(0.391)$ \\
& & & \\
Constant & 1.971 & -0.415 & -0.415 \\
& $(1.381)$ & $(2.682)$ & $(2.682)$ \\
& & & \\
Observations & 31 & 31 & 31 \\
R-squared & 0.734 & 0.691 & 0.691 \\
\hline
\end{tabular}

Robust standard errors in parentheses ${ }^{* * *} \mathrm{p}<0.01,{ }^{* *} \mathrm{p}<0.05,{ }^{*} \mathrm{p}<0.1$

While these results have to be taken with great care given the unstructured nature of our specification, labor market variables do not seem to have much explanatory power beyond the changes in GDP. With the exception of employment at the 2015 horizon, none of the other variables are significant. This does not mean that the labor market does not matter, as it is behind the initial change in GDP, but it shows that differences in labor market performance among two countries with similar GDP changes in the earlier years does not significantly improve our understanding the long-term persistence of GDP. And the fact that the significance is only present at a shorter horizon is consistent with the logic that labor market outcomes might be persistent over several years but they tend to return to normal over a longer horizon. The very long-term persistence of GDP needs to be explained by other factors such as physical capital or productivity. 
Table 3. Persistence of Forecast Errors Real GDP. Advanced Economies.

\begin{tabular}{lcccc}
\hline Advanced & \multicolumn{5}{c}{ Forecast Error Real GDP } \\
& 2015 & 2021 & 2015 & 2021 \\
\hline & & & & \\
Forecast error & $1.198^{* * *}$ & $1.658^{* * *}$ & $1.377^{* * *}$ & $1.811^{* * *}$ \\
GDP 2009 & $(0.181)$ & $(0.249)$ & $(0.287)$ & $(0.355)$ \\
& & & & \\
Forecast error & $0.483^{* *}$ & 0.397 & & \\
Employment 2009 & $(0.215)$ & $(0.322)$ & & \\
& & & -0.171 & -0.120 \\
Forecast error & & & $(0.684)$ & $(0.818)$ \\
Unemployment & & & & \\
2009 & & & & \\
& & & -2.292 & -2.862 \\
Constant & $-3.538^{* *}$ & -3.897 & $(1.774)$ & $(2.625)$ \\
& $(1.596)$ & $(2.423)$ & & \\
Observations & 34 & 34 & 34 & 34 \\
R-squared & 0.641 & 0.617 & 0.612 & 0.605 \\
\hline
\end{tabular}

Robust standard errors in parentheses

${ }^{* * *} \mathrm{p}<0.01,{ }^{* *} \mathrm{p}<0.05,{ }^{*} \mathrm{p}<0.1$

\subsection{Persistence or permanent effects?}

So far we have seen that an unexpected change in GDP was very persistent and that the 2015 or 2021 forecasts were revised by an amount that is as large or larger than the initial impulse. Will these persistent effects ever die out? Or will these persistent effects become permanent?

One way to address this question is to make use of measures of potential output. Potential output can be seen as a long-term forecast for GDP given the available information today. The distance between potential output and GDP (the output gap) is an indication of the possibility that GDP will return to previous trend in the future. If cyclical events are seen as transitory, a fall in GDP should lead to no change in potential output. But if the changes in GDP as seen as having not just a persistent effect but a permanent effect on output, then potential output will be revised downwards. In that sense, the estimates of potential output offer us an 
opportunity to look into the persistent effects of this crisis even beyond the year 2021.

We now replicate our previous regressions but using as dependent variable the forecast error of potential GDP for the same three years (2012, 2015 and 2021). ${ }^{12}$ We once again use the unexpected change in GDP during 2006-09 as our measure of the initial shock and we ask how potential output changed relative to what we had earlier anticipated (Table 4).

Table 4. Persistence of Forecast Errors Potential GDP. Advanced Economies.

\begin{tabular}{|c|c|c|c|}
\hline & \multicolumn{3}{|c|}{ Forecast Error Potential GDP } \\
\hline & 2012 & 2015 & 2021 \\
\hline Forecast Error & $1.174^{* * *}$ & $1.537^{* * *}$ & $1.843^{* * *}$ \\
\hline Real GDP 2009 & $(0.295)$ & $(0.365)$ & $(0.421)$ \\
\hline Constant & $\begin{array}{l}-0.188 \\
(2.041)\end{array}$ & $\begin{array}{l}-1.186 \\
(2.360)\end{array}$ & $\begin{array}{l}-4.642^{*} \\
(2.566)\end{array}$ \\
\hline Observations & 29 & 29 & 29 \\
\hline R-squared & 0.448 & 0.440 & 0.399 \\
\hline
\end{tabular}

The estimates suggest that the revisions to potential output were very large as well. In fact the size of the coefficients in Table 4 are very similar to what we found in Table 2 , suggesting that the large revisions to GDP are becoming permanent, as captured by the change in potential output. As an example, the unexpected decrease in GDP until 2009 can help explain a decrease in about 1.8 percentage points of potential output in 2021, slightly smaller than the 2.1 percentage points we found for GDP. Another way to reach the same conclusion is to look at current estimates of output gap. While they signal some expected

\footnotetext{
${ }^{12}$ Calculating forecast errors for potential output is more complicated than for GDP. Potential output is not observed but estimated. In addition, revisions to current level of potential output tend to lead to revisions of past levels of potential output. In our calculations we ignore these historical revisions. What we are comparing is how our view of future potential output changes as time passes. This means that we cannot simply compare forecast errors in growth rates as we did with GDP. We explain in detail the methodology we use to deal with ex-post revisions to potential output estimates in an appendix at the end of the paper.
} 
recovery in the years ahead, this recovery is much smaller than the output that has been lost so far, the losses have become permanent.

While these effects seem to be present across all 29 advanced economies, they are stronger in some countries. Table 5 repeats the same exercise for the sample of European countries and Euro members. Overall the coefficients are the largest among the Euro members.

Table 5. Persistence of Forecast Errors Potential GDP in the Euro Area.

\begin{tabular}{lccc|ccc}
\hline & \multicolumn{3}{c|}{ Europe } & \multicolumn{3}{c}{ Euro } \\
& 2012 & 2015 & 2021 & 2012 & 2015 & 2021 \\
\hline & & & & & & \\
Forecast Error & $1.136^{* * *}$ & $1.482^{* * *}$ & $1.851^{* * *}$ & $1.802^{* * *}$ & $2.207^{* *}$ & $2.760^{* *}$ \\
Real GDP 2009 & $(0.380)$ & $(0.466)$ & $(0.556)$ & $(0.575)$ & $(0.838)$ & $(1.017)$ \\
& & & & & & \\
Constant & -1.471 & -2.646 & -4.603 & 3.446 & 2.120 & 0.759 \\
& $(2.894)$ & $(3.368)$ & $(3.890)$ & $(4.069)$ & $(6.089)$ & $(7.650)$ \\
Observations & 19 & 19 & 19 & 13 & 13 & 13 \\
R-squared & 0.390 & 0.361 & 0.336 & 0.480 & 0.400 & 0.388 \\
\hline
\end{tabular}

Robust standard errors in parentheses

${ }^{* * *} \mathrm{p}<0.01,{ }^{* *} \mathrm{p}<0.05,{ }^{*} \mathrm{p}<0.1$

\section{Is the persistence of GDP surprising? Literature review.}

\subsection{Output shocks tend to be persistent.}

So far we have shown that the shock that hit advanced economies after 2007 has been very persistent. More than eight years after the crisis started the current level of output as well as the estimates of potential GDP are much lower than expected. It is by now well accepted that these countries will not regain their pretrend crisis levels.

In many ways this should not be a big surprise, since we know from the pioneering work of Nelson and Plosser (1982) that fluctuations are persistent and that US GDP displays a unit root in GDP. And Campbell and Mankiw (1989), among others, later confirmed that this persistence is also present for G7 
countries: a $1 \%$ fall in output lowers its long-term projection by more than $1 \%$, consistent with our findings.

The large persistence is also supported by an empirical literature that has studied the long-term permanent effects of large crises. The focus of this literature is typically only on negative shocks ("crises") that are large and clearly identifiable in the data.

Many of the papers have studied either emerging markets (where crises tend to be larger) or financial crises that tend to be characterized by deep and protracted recessions. The evidence shows that output fails to catch up with its previous trend after any of these large events.

Cerra and Saxena (2008) produce evidence that after financial and political crises output losses are very persistent even after taking into account the possibility of endogeneity. Using a much longer time horizon Reinhart and Rogoff (2014) also show that recovery from financial crisis is slower than from regular crisis (similar results in International Monetary Fund (2009), Jordà, Schularick, and Taylor (2011) or Claessens, Kose, and Terrones (2011)). ${ }^{13}$

Some of these papers assess directly the effect that financial crises have on potential output. Furceri and Mourougane (2012) show that financial crisis have a significant effect on potential output for OECD economies. Ball (2014) focuses on the Great Recession to show that potential output has been reduced significantly among OECD countries.

The strong persistence of recessions applies to more than just large financial crisis. Blanchard, Cerutti, and Summers (2015), Martin and Wilson (2013) and Haltmaier (2013) show that across all recessions in advanced economies over the last 40 years GDP is very persistent. More interestingly, they also show that potential output is consistently revised downwards during crisis years. This is very much consistent with the evidence we have presented in the previous section.

\footnotetext{
${ }^{13}$ Although others have expressed partial disagreement with this assessment. Howard, Martin, and Wilson (2011) show that recoveries are in fact very quick after deep financial crisis although they agree that they are very slow after long financial crisis. And Bordo and Haubrich (2012) or Romer and Romer (2014) present an even more dissenting view about why financial crisis are special using data for US or advanced economies.
} 
A related, although separate literature, emphasizes the persistent or permanent effects of recessions on the labor market. The literature started with the observation that European unemployment failed to return to its pre-crisis level during the 70s (Blanchard and Summers (1986)). The literature has recently regained some interest because of the persistent behavior of unemployment and, in particular, long-term unemployment, during the Great Recession mainly in Europe but also in the US.

\subsection{Interpreting the persistence of shocks (and large crises).}

The early evidence on the persistence of GDP shocks, both positive and negative, provided support to theories where technology shocks were the driving force of business cycles (RBC). Traditionally, the trend was seen as driven by a standard growth model (e.g. Solow) and models of the business cycles, even those based on Keynesian views of fluctuations, assumed that booms and recessions represented deviations from this trend.

The fact that Nelson and Plosser (1982) showed that the trend itself was stochastic and its variance could account for a large amount of the GDP variation was seen as evidence that technology shocks were a significant driving force of fluctuations. In fact, the persistence of shocks was used as a way to separate demand (temporary) from supply (permanent) sources of shocks as in Blanchard and Quah (1989).

But there is also a very different interpretation of the persistence of GDP, if we are willing to deviate from the tradition of separating long-term dynamics and business cycles. It is possible that cyclical conditions leave permanent scars on output, what is typically referred to as hysteresis. It was originally applied to models of the labor market as in Blanchard and Summers (1986) where cyclical unemployment turned into structural one. But the logic extends even more naturally when we start thinking of long-term growth as endogenous and we allow for the possibility that economic cycles interrupt temporarily these longterm dynamics. Stadler (1990) showed how in endogenous growth models any type of shock has permanent effects on GDP because it temporarily affects the underlying growth dynamics. During recessions, investment is lower, R\&D expenditures are lower and trend growth happens at a lower pace that during normal years. Fatás (2000) presents a similar model as well as evidence supporting this logic. 
The difficulty of separating these two hypothesis (technology shocks versus hysteresis) is dealing with endogeneity. The literature has followed several approaches to providing evidence supporting hysteresis. First, variables that drive trend growth are indeed affected by cyclical conditions (e.g. investment and R\&D expenditures are procyclical). Second, there is a correlation between the growth process and the persistence of fluctuations (Fatás (2000) shows that persistence is correlated to average growth rates). Finally, we can also avoid endogeneity if we are able to identify specific shocks that are cyclical in nature (such as monetary or fiscal policy shocks) and then analyze the persistence of GDP in response to these shocks. Blanchard, Cerutti, and Summers (2015) show that recessions that are caused by demand shocks tend to be very persistent. International Monetary Fund (2009) presents evidence that during the Asian crisis, countries with stronger countercyclical policies had less persistent fluctuations. We follow this last strand of the literature by studying the cyclical movements in output that resulted from the widespread 2009-11 fiscal consolidations to understand how much they can explain the observed persistence in GDP.

\section{Cyclical or structural? A test using the 2009-11 fiscal consolidation.}

\subsection{Identifying fiscal policy shocks.}

We have documented in Section 2 that the crisis that started in 2007 has turned to be very persistent across all countries. From our discussion in Section 3 we understand that there are two potential explanations. First, it could be that the depth of the crisis is simply driven by changes in potential output. For this to be true, it would have to be that during the years 2008-15 these countries have suffered structural changes that have made forecasters revise downwards the estimates of potential output. These changes must have had a country-specific component that explains the cross-country variation. And the changes must have been unanticipated; i.e. aging and demographic changes could be relevant to understand dynamics of potential output but they were anticipated before the crisis.

The second explanation for persistence is that country-specific factors (such as economic policies or labor market characteristics or pre-crisis dynamics) have generated variation in the depth and length of the crisis that has translated into a fall in potential output via hysteresis effects. 
Separating these two effects from an empirical point of view is challenging. Ideally one needs to identify exogenous movements in macroeconomic variables that can be used to identify one the direction in which causality runs. This issue is no different from the endogeneity problems of the literature on fiscal policy multipliers and the debate about the effects of austerity: we know that fiscal policy austerity seems to be correlated with decreases in output but in which direction does causality run?

In the context of the fiscal policy multiplier debate Blanchard and Leigh (2013) introduced a simple methodology to deal with endogeneity in order to measure the impact of the 2009-2010 fiscal consolidations in European economies. Their methodology is in many ways similar to the identification assumptions of more complex econometric specification (such as a VAR) but in a much simpler framework. Their methodology relies on the fact that GDP forecast errors should be uncorrelated with fiscal policy if the model used to generate the forecasts has the right assumptions about fiscal policy multipliers. If we find that the correlation is negative and significant it means that the model is underestimating fiscal policy multipliers.

We make use of their methodology to explore how fiscal policy can be responsible for the changes in both GDP over a longer horizon and potential output during the years that followed the fiscal consolidation. In other words, we make use of their methodology to identify a shock to fiscal policy and then assess the long-term response of GDP as well as the effects of potential output to this shock.

We start by replicating the results of Blanchard and Leigh (2013). We use the same years, 2010 and 2011 where fiscal consolidations were planned and executed among many economies. We also focus on the same set of countries: European countries among the advanced economies. We collect data from the April 2010 WEO and measure the planned fiscal consolidation over the next two years (2010 and 2011) as the change in the forecast of the change in the structural balance as a percentage of potential GDP $\left(\Delta S B_{i, 2010-2011}^{F}\right)$. This is identical to the specification in Blanchard and Leigh (2013) and this magnitude can be thought of as the size of the planned fiscal consolidation. We then measure the forecast error for real GDP in the level of output for different years $(t)$.

The forecast error is computed using the data available $\left(G D P_{i, t}\right)$ from the IMF World Economic Outlook of April 2016 against the forecast made in April 2010. 
$\left(G D P_{i, t}^{F, 2010}\right)$. We then regress the forecast error on the planned fiscal consolidation.

$$
F E_{G D P, t}^{2010}=\frac{G D P_{i, t}-G D P_{i, t}^{F, 2010}}{G D P_{i, t}^{F, 2010}}=\alpha+\beta \Delta S B_{i, 2010-2011}^{F, 2010}+\varepsilon_{i}
$$

Under the assumption that the forecast had been made using the right fiscal policy multipliers, the coefficient $\beta$ should be equal to zero. Blanchard and Leigh (2013) found that the coefficient was negative, large and significant, a sign that fiscal policy multipliers had been underestimated by the IMF model.

Table 6. Blanchard and Leigh Replication.

\begin{tabular}{lcc}
\hline & \multicolumn{2}{c}{ Forecast Error GDP } \\
& Europe & Euro \\
\hline & 2011 & 2011 \\
\hline \multirow{2}{*}{ Fiscal Consolidation } & $-1.341^{* *}$ & $-1.534^{* *}$ \\
$2009-10$ & $(0.530)$ & $(0.578)$ \\
& & \\
Constant & $1.150^{* * *}$ & $1.340^{* * *}$ \\
& $(0.402)$ & $(0.393)$ \\
& & \\
Observations & 22 & 14 \\
R-squared & 0.500 & 0.609 \\
\hline
\end{tabular}

Robust standard errors in parentheses ${ }^{* * *} \mathrm{p}<0.01,{ }^{* *} \mathrm{p}<0.05,{ }^{*} \mathrm{p}<0.1$

When we replicate their results for 2011 (Table 6), we find almost identical result (there are small differences because of slightly different sample and because the data has been revised since their analysis). We find a coefficient of about 1.3 for Europe as a whole, similar to their results, and slightly larger if we restrict the sample to Euro countries. Remember that the forecast made by the IMF in April 2010 for the next two years already assumed that fiscal consolidation would affect GDP with a multiplier of 0.5 . In that sense, the coefficient $\beta$ here represents the effects of fiscal consolidation in addition to that assumed multiplier (0.5). Given the coefficient of 1.3 the estimated multiplier is around 1.8 for Europe and closer to 2 for the Euro members. 


\subsection{The persistent effects of fiscal policy shocks.}

Using the methodology of Blanchard and Leigh (2013) we have identified movements in GDP that are associated to the fiscal consolidations that took place during the years 2009-2011. We now want to assess how persistent these changes in GDP were and whether they were also reflected in changes in potential output.

In order to capture these effects, we run a two-stage procedure: we first regress changes in output during the earlier years of the crisis (2010-11) on the planned fiscal consolidation during those years (this is identical to the Blanchard and Leigh (2013) specification of Table 6):

$$
F E_{G D P, 2011}^{2010}=\frac{G D P_{i, t}-G D P_{i, t}^{F, 2010}}{G D P_{i, t}^{F, 2010}}=\alpha+\beta \Delta S B_{i, 2010-2011}^{F, 2010}+\varepsilon_{i}
$$

We now use the fitted values from this regression $\widehat{F E}_{G D P, 2011}^{2010}$ as the explanatory variable to understand unexpected changes in GDP over longer horizons.

$$
F E_{G D P, t}^{2010}=\alpha+\beta \widehat{F E}_{G D P, 2011}^{2010}+\varepsilon_{i}
$$

The interpretation of this second regression is that we are measuring the effects on long-term GDP of changes that took place during 2010-11 that were caused by the fiscal consolidation during those two years. In other words, we are isolating changes in GDP that are caused by identifiable changes in demand (via fiscal policy) and assessing whether they become persistent over time.

The estimates of Table 7 show that the fiscal-policy-induced changes in GDP in the years 2009-2011 were very persistent. A 1\% change in GDP led to changes in more than $1 \%$ by 2015 and around $2 \%$ by the year 2021 . These results are consistent with our early analysis of persistence but now we are identifying movements in output that we have identified as driven by fiscal policy, so we can see the long-term damage of fiscal consolidations. ${ }^{14}$

\footnotetext{
${ }^{14}$ Our 2SLS can be interpreted as an IV estimation of the long-term effects of cyclical changes in GDP using fiscal policy as an instrument. A Durbin-Wu-Hausman test shows that the hypothesis of exogeneity in the OLS estimates cannot be rejected. This means that the persistent effects
} 
Table 7. Long-Term Effects of Fiscal Consolidation. 2SLS Estimation.

\begin{tabular}{lcccc}
\hline \multicolumn{4}{c}{ Europe } & \multicolumn{2}{c}{ Euro } \\
\hline & 2015 & 2021 & 2015 & 2021 \\
\hline \multirow{F}{*}{$\widehat{F E}_{G D P, 2011}^{2010}$} & $1.176^{* *}$ & $2.061^{* * *}$ & $1.299^{* *}$ & $2.099^{* * *}$ \\
& $(0.462)$ & $(0.501)$ & $(0.439)$ & $(0.559)$ \\
& & & & \\
Constant & $-4.980^{* * *}$ & $-4.700^{* * *}$ & $-5.441^{* * *}$ & $-5.239^{* *}$ \\
& $(0.997)$ & $(1.481)$ & $(1.315)$ & $(2.086)$ \\
& & & & \\
Observations & 22 & 22 & 14 & 14 \\
R-squared & 0.575 & 0.540 & 0.657 & 0.607 \\
\hline
\end{tabular}

Robust standard errors in parentheses ${ }^{* * *} \mathrm{p}<0.01,{ }^{* *} \mathrm{p}<0.05,{ }^{*} \mathrm{p}<0.1$

The fact that the coefficient is similar across the two samples does not mean that the overall effects are the same. We are not measuring a fiscal policy multiplier in this table, we are capturing the extent to which short-term changes in GDP became persistent. In Table 6 we have shown that the short-term multiplier was larger for the Euro members. Given that now we can see that the persistence is similar for both samples, it means that the initial larger multiplier is also translated into larger permanent effects for the Euro countries.

We can now test whether a similar pattern is observed when looking at potential output. We estimate these effects using the same 2SLS procedure. The first-stage regression is the same as before and for the second-stage regression we know use forecast errors of potential GDP on the left-hand side of our regression:

$$
F E_{P G D P, t}^{2010}=\alpha+\beta \widehat{F E}_{G D P, 2011}^{2010}+\varepsilon_{i}
$$

The results of Table 8 confirm that the effects of fiscal policy are seen as permanent, having an effect on our current estimates of potential output that are as large or larger than the cyclical effect on GDP. The estimated coefficient is

identified by our 2SLS estimation are not different from the effects of any other cyclical movements in GDP (those unrelated to fiscal policy). This is not a surprise, and it simply confirms that the persistence of cyclical movements in GDP is not particular to dynamics created by fiscal policy shocks. 
very large. It suggests that not only the temporary effects of fiscal consolidation do not die out over time but that the long-term effects are likely to be larger than the initial ones. Every 1\% fiscal-policy-induced decline in GDP during the years 2010-11 translated into a 1\% decline in potential output by 2015 and even more for 2021.

Table 8. Permanent Effects of Fiscal Consolidation. 2SLS Estimation.

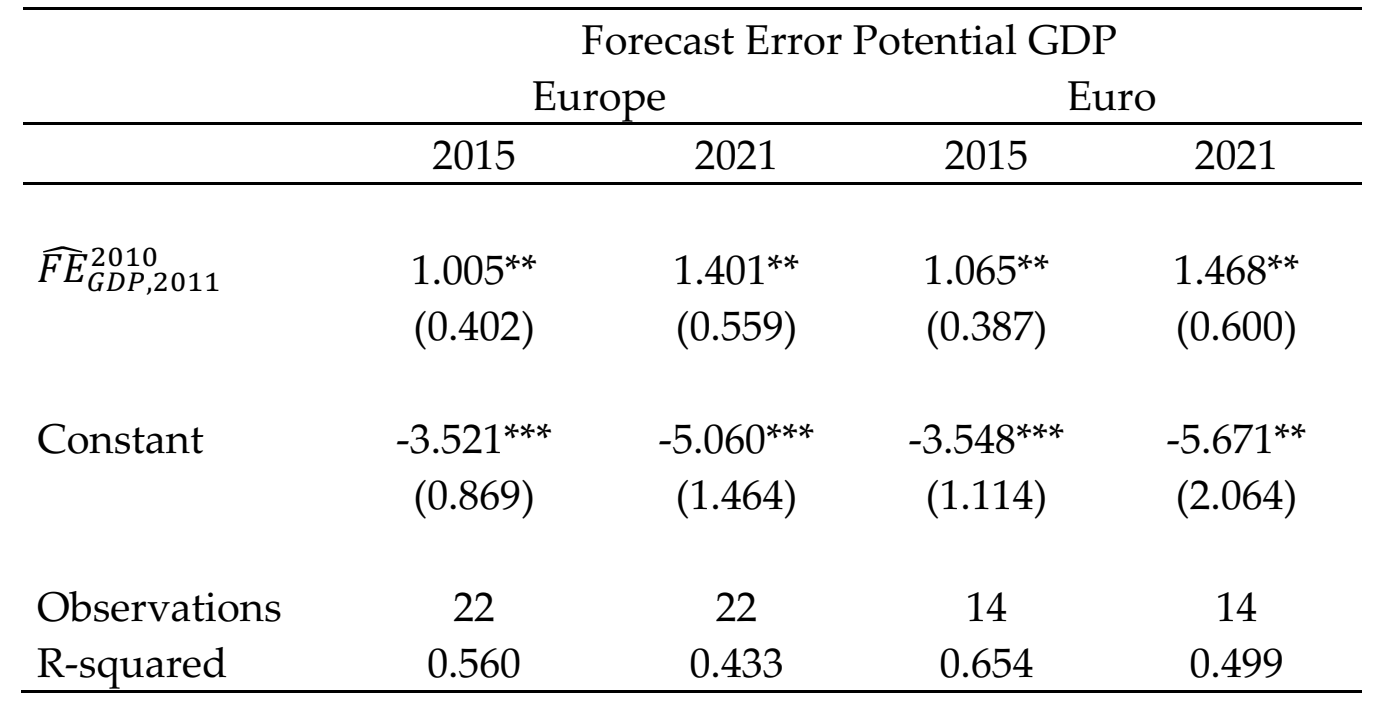

Robust standard errors in parentheses *** $\mathrm{p}<0.01,{ }^{* *} \mathrm{p}<0.05,{ }^{*} \mathrm{p}<0.1$

The results are significant for both samples with similar coefficients for the Europe and Euro samples. And looking at the R-squared, the short-term fiscalpolicy-induced movements in GDP can explain a large percentage of the variation in potential output across countries, as much as $65 \%$.

\subsection{Interpreting our results. Are there alternative explanations?}

We have exploited the strong cross-country correlation between the fiscal consolidations in 2010-11 period and the subsequent changes to GDP and potential output to claim that fiscal policy has had large and permanent effects on GDP. The effects might seem very large but we need to keep in mind that our estimates take place during the worst recession since the Great Depression at a time when monetary policy was constrained by the zero-lower bound in many countries. In addition, for the countries inside the Euro area monetary and exchange rate policies were unavailable at the country level. 
As Blanchard and Leigh (2013) show, applying the same methodology to other periods of time where these conditions do not apply produce much smaller effects of fiscal policy on output. We would expect our results to be also weaker for those periods.

When it comes to interpreting the size of our coefficients one needs to be careful. While our specification is based on the analysis of fiscal policy multipliers of Blanchard and Leigh (2013), we are looking at a longer horizon which makes the interpretation of our estimates as multipliers less. In their analysis by matching the timing of the fiscal consolidation to the change in the forecast error for GDP one could argue that the variation in changes in GDP is directly related to fiscal policy changes (which constitutes the standard definition of multipliers). ${ }^{15}$

In our case we extend the horizon by an additional four to eight years beyond the years where the fiscal policy changes are taking place. In that sense, it is possible that we are capturing some additional effects. In particular, the initial fiscal policy shock could be correlated (across countries) with similar shocks in the years ahead that also have an effect on GDP or potential. While this makes more difficult the interpretation of our estimates as multipliers, we see this possibility as strengthening the story we want to tell from our analysis. ${ }^{16}$

Countries that implemented large fiscal consolidations in 2010-11 might have found themselves in 2012 with a depressed economy that might have required even larger adjustments in fiscal policy that further depressed future growth. If this is true, as we move the timing of GDP to 2015 and 2021 we are likely to capture in our estimates also the effects of potential second-round fiscal consolidations. But in many ways these can be seen as the outcomes of the first policy decisions. In that sense, the fact that the final effects on GDP are correlated with the initial fiscal policy shock suggests that our estimates are capturing the full consequences of those policy decisions.

\footnotetext{
${ }^{15}$ Of course, there could be longer-term effects on GDP that are not captured in their analysis but as long as we believe that the majority of the effects of fiscal policy shocks are felt contemporaneously, the estimate of multipliers will be close enough.

${ }^{16}$ The fact that in many of our results the short-term effects are amplified as time passes suggests that either there are other shocks that follow and are correlated with the initial one or the presence of "superhysteresis". It might be that not only the level of GDP is affected by the crisis but also its growth rate, in a persistent manner. Studying these interesting issues is beyond the scope of this paper and probably requires additional data to test each of these hypotheses.
} 
We make use of estimates of potential GDP because they provide us with a better sense on the long-term dynamics of output and a view on the permanent effects on GDP. And as shown in Table 8, our estimates using potential output confirm our results using GDP. The fiscal policy contraction of 2009-11 had an impact on our views on potential output today (2015) which confirms the change in GDP forecast we have constructed for 2021.

The use of potential output could raise some concerns because it is a constructed variable that might be following GDP too closely and not capturing an accurate and independent long-term forecast of GDP. This is possible but it is very unlikely for two reasons. First, our results with potential output match the results using GDP over a long-enough horizon, one that should be avoiding contamination from cyclical dynamics. The fact that the value of GDP in 2015 or its current forecast for 2021 are affected by the fiscal changes in 2010-11 are already a good indication that these effects are extending over a very long horizon. Second, if potential output was being wrongly estimated by simply extrapolating the cyclical dynamics of GDP it would mean that over the next years we would be expecting a very strong recovery in countries most affected by the crisis. For example, we would be expecting Greece to deliver extremely fast growth rates over the coming years not only to recover the $25 \%$ lost GDP but in addition to catch up with the previous pre-crisis trend. This sounds very implausible. There are no current forecasts of GDP from any national government or international organization that suggests this will be the case.

While one can never rule out the possibility of a surprising performance from European countries in the years ahead, all information currently available points in the direction that the GDP losses they have suffered are indeed permanent. Ideally we would like to wait 10 more years and run similar regressions using GDP in 2025. In the absence of actual data for GDP for 2025, our analysis provides the best estimates one can do of the long-term effects of the economic policy choices countries made during the global financial crisis.

\section{Was the fiscal consolidation self-defeating?}

Our estimates suggest that the fiscal contraction in European economies reduced output not only in the short term but also in the medium term and possibly on a permanent basis. This reduction in output makes the goal of the fiscal consolidation harder as it raises the ratio of debt to GDP and it reduces tax revenues. 
This is a point made by DeLong and Summers (2012) who argue that in a depressed economy a fiscal consolidation can be self-defeating, it can lead to an increase in debt. To understand the logic, and following closely their analysis, let $D_{t}$ be the level of government debt, $G_{t}$ spending, $T_{t}$ taxes and $Y_{t}$ the level of GDP in year $t$. Imagine a government that introduces a fiscal consolidation plan that involves a decrease in spending.

$$
\Delta G_{t}=G_{t+1}-G_{t}
$$

where $G_{t+1}$ refers to the level of government spending planned for next year which we assume matches its execution. But the change in spending is likely to affect negatively GDP next year. The change in GDP will depend on the fiscal policy multiplier $(\mu)$.

$$
\Delta Y_{t}=\mu \Delta G_{t}
$$

The level of debt will be reduced by

$$
\Delta D_{t}=\Delta G_{t}-\Delta T_{t}=\Delta G_{t}-\mu \tau \Delta G_{t}=(1-\mu \tau) \Delta G_{t}
$$

This reduction in the level of debt imposes a burden on future government balances equal to

$$
(\mathrm{r}-\mathrm{g}) \Delta D_{t}=(\mathrm{r}-\mathrm{g})(1-\mu \tau) \Delta G_{t}
$$

Where $r$ is the government borrowing rate and $g$ is the long-run growth rate of GDP.

Assume some permanent effects of the recession caused by the fiscal consolidation. In particular potential output is likely to change by an amount $\left(\Delta Y_{t}^{p}\right)$ that is related to the cyclical change in output $\left(\Delta Y_{t}^{c}\right)$.

$$
\Delta Y_{t}^{p}=\eta \Delta Y_{t}^{c}=\eta \mu \Delta G_{t}
$$

Where the parameter $\eta$ is the hysteresis parameter. Because of this change in output there will be a permanent loss of revenues equal to

$$
\tau \Delta Y_{t}^{p}=\tau \eta \mu \Delta G_{t}
$$

A fiscal contraction is self-defeating as long as 


$$
\tau \eta \mu>(\mathrm{r}-\mathrm{g})(1-\mu \tau)
$$

DeLong and Summers (2012) calibrate the above parameters for the US economy. Assuming plausible values for $g$ and $r$, they look for combination of parameter values for the short-run fiscal multiplier and the hysteresis parameter that make the above equation hold. The range of values they consider for the fiscal multiplier is between 0-2.5. Our analysis above, following Blanchard and Leigh (2013) produces a multiplier of about 1.8. Given this number and using DeLong and Summers (2012) calibration, the hysteresis parameter would have to be between 0 and 0.025 (this is assuming a real treasury rate between 2.5 and $5 \%$ ).

How does this correspond to our estimates of the permanent effects of fiscal consolidations? If we take our results at face value, the hysteresis effect is much larger than any of these values. For example, if look at the regression of Table 8 we see permanent effects that are similar or than those during the years 2009-11. If we identify those years as the cyclical changes in output then we would be calibrating the parameter $\eta$ to be at or above 1, much higher than the required level. Therefore, our results strongly suggest that the fiscal consolidation that took place during those years was self defeating and instead of delivering the outcome of reducing debt, it led to an increase.

The idea that a government trying to restore debt sustainability should opt for spending more can be seen as implausible, or as some might call a "free lunch" (Rogoff (2015)). Our results do not suggest in any way that this is a standard policy advise for all governments at all times. We are looking at a particular episode where several special circumstances are coming together. First, for many of these countries monetary policy was constrained either by the zero-lower bound or because of the institutional arrangements of the Euro area. This is likely to generate larger short-term fiscal policy multipliers (Eggertsson (2011) and Eggertsson and Krugman (2012)). Second, this was a very deep crisis with growth rates reaching negative numbers that had not been seen since the Great Depression. In addition, the nature of the crisis made the recession long and the recovery slow. This persistent short-run dynamics are likely to leave a much larger permanent effects on output through hysteresis effects (see Blanchard, Cerutti, and Summers (2015)). In the case of the Great Recession, this hysteresis effects are the outcome not only of very persistent labor market dynamics but of a depressed behavior of investment that results in a much lower capital stock (see evidence in International Monetary Fund (2015)). 
Hysteresis is crucial for the possibility of self-defeating fiscal consolidations. A lower permanent level of output increases the debt-to-GDP ratio and it also reduces the level of tax revenues. Because output is likely to trend upwards, so are fiscal variables. While the recipe for a government with high debt is likely to be a lower spending to GDP ratio, reducing spending and, as a result, GDP by a similar amount not only does not achieve its objective but it leads to a higher debt-to-GDP ratio. And the fact that some or all of the change in output is permanent, makes austerity the wrong fiscal policy.

Our conclusion that to achieve any target effect on aggregate demand countercyclical fiscal policy would have to be more aggressive given the nature and persistence of the crisis also applies to monetary policy. As suggested in Blanchard, Cerutti, and Summers (2015), the fact that cyclical shocks are likely to have permanent effects on output calls for a much stronger stabilization policy when policy makers seek to offset negative shocks to aggregate demand.

A final caveat regarding our reading of the empirical results. We are talking about the potential benefits of having had a more expansionary fiscal policy. It is possible that for some countries there was no alternative because financial markets had completely cut access to additional. For capital markets to deny funding a less contractionary fiscal policy it must be that our logic was not shared or properly understood by capital markets at that point. Because if our results are correct and both governments and markets agreed with our logic, capital should continue to flow to support a fiscal policy that might be expansionary but it promotes a reduction in the debt-to-GDP ratio. In addition, even if markets do not accept the logic of our conclusions, it would be up to international organizations (IMF or other governments not constrained in their funding) to decide on additional funding to support the right type of fiscal policy in the constrained economies, one that truly produces a more sustainable budgetary position.

\section{Conclusions}

The global financial crisis has permanently lowered the path of GDP in all advanced economies. In none of these countries GDP is expected to return to its pre-crisis trend. At the same time, many of these countries have been engaging in fiscal consolidations in response to rising government debt levels that had a negative impact on growth rates. In this paper we use the methodology of Blanchard and Leigh (2013) to show that fiscal consolidations had long-term 
effects on GDP, at a horizon much longer than the traditional analysis of fiscal policy multipliers. Our results strongly suggest that the negative effects on GDP are indeed permanent.

We have first documented the persistence of the effects of the global financial crisis. They are visible both in the current level of GDP and in the IMF forecasts for 2021. In addition, we show that potential output has been revised downwards by a similar amount, a sign that the reduction in GDP is mostly seen as permanent, i.e. there is strong evidence of hysteresis.

While permanent changes in GDP could be associated to structural changes in economic conditions (e.g. productivity shocks or changes in demographics), we exploit the cross-country variation in persistence to show that a significant part of the changes in actual and potential GDP are the direct result of the fiscal consolidation implemented during the period 2009-2011.

The combination of strong cyclical effects of fiscal policy and hysteresis provides support to the hypothesis of self-defeating fiscal consolidations of DeLong and Summers (2012). If the negative effects of fiscal consolidation are long lasting, countries can enter a negative loop where attempts to reduce government debt are not effective because of the reductions in GDP. As GDP falls permanently, attempts to reduce debt via reductions in spending or increases in taxes lead to a higher debt to GDP ratio. Using our empirical results we produce a quick calibration of the model of DeLong and Summers (2012) and show that the calibrated parameter values support the notion of self-defeating fiscal consolidations for the group of advanced economies, more so for the Euro countries.

\section{References.}

Ball, Laurence, 2014, Long-Term Damage from the Great Recession in OECD Countries, National Bureau of Economic Research, Cambridge, MA.

Blanchard, Olivier, Eugenio Cerutti, and Lawrence H. Summers, 2015, Inflation and Activity, . ManuscriptManuscript.

Blanchard, Olivier Jean, and Danny Quah, 1989, The Dynamic Effects of Aggregate Demand and Supply Disturbances, American Economic Review 79, 655673. 
Blanchard, Olivier J., and Daniel Leigh, 2013, Growth forecast errors and fiscal multipliers, National Bureau of Economic Research.

Blanchard, Olivier J., and Lawrence H. Summers, 1986, Hysteresis and the European unemployment problem, NBER Macroeconomics Annual 1986, Volume 1 (Mit Press).

Bordo, Michael D., and Joseph G. Haubrich, 2012, Deep recessions, fast recoveries, and financial crises: evidence from the American record, National Bureau of Economic Research.

Campbell, John Y., and N. Gregory Mankiw, 1989, International evidence on the persistence of economic fluctuations, Journal of Monetary Economics 23, 319-333.

Cerra, V., and S.C. Saxena, 2008, Growth dynamics: the myth of economic recovery, The American Economic Review 98, 439-457.

Claessens, Stijn, M. Ayhan Kose, and Marco E. Terrones, 2011, How do business and financial cycles interact?, Journal of International Economics.

DeLong, J. Bradford, and Lawrence H. Summers, 2012, Fiscal Policy in a Depressed Economy [with Comments and Discussion], Brookings Papers on Economic Activity, 233-297.

Eggertsson, Gauti B., 2011, What fiscal policy is effective at zero interest rates?, NBER Macroeconomics Annual 2010, Volume 25 (University of Chicago Press).

Eggertsson, Gauti B., and Paul Krugman, 2012, Debt, deleveraging, and the liquidity trap: A fisher-minsky-koo approach*, The Quarterly Journal of Economics.

Fatás, Antonio, 2000, Endogenous growth and stochastic trends, Journal of Monetary Economics 45, 107-128.

Fatás, Antonio, 2000, Do business cycles cast long shadows? Short-run persistence and economic growth, Journal of Economic Growth 5, 147-162.

Furceri, Davide, and Annabelle Mourougane, 2012, The effect of financial crises on potential output: new empirical evidence from OECD countries, Journal of Macroeconomics 34, 822-832.

Haltmaier, Jane, 2013, Do recessions affect potential output?, FRB International Finance Discussion Paper. 
Howard, Greg, Robert Martin, and Beth Anne Wilson, 2011, Are Recoveries from Banking and Financial Crises Really So Different? (Federal Reserve Board).

International Monetary Fund, 2009, What's the Damage? Medium-Term Output Dynamics after Financial Crises, World Economic Outlook Chapter 4.

International Monetary Fund, 2015, Where Are We Headed? Perspectives on Potential Output., World Economic Outlook Chapter 3.

Jordà, Òscar, Moritz HP Schularick, and Alan M. Taylor, 2011, When credit bites back: leverage, business cycles, and crises, National Bureau of Economic Research.

Martin, Robert, and Beth Anne Wilson, 2013, Potential Output and Recessions: Are We Fooling Ourselves?, Manuscript.

Nelson, Charles R., and Charles R. Plosser, 1982, Trends and random walks in macroeconmic time series: some evidence and implications, Journal of monetary economics 10, 139-162.

Reinhart, Carmen M., and Kenneth S. Rogoff, 2014, Recovery from Financial Crises: Evidence from 100 Episodes, American Economic Review 104, 50-55.

Rogoff, Kenneth, 2015, A New Deal for Debt Overhangs?, Project Syndicate.

Romer, Christina D., and David H. Romer, 2014, New Evidence on the Impact of Financial Crises in Advanced Countries, Manuscript.

Stadler, George W., 1990, Business cycle models with endogenous technology, The American Economic Review, 763-778. 


\section{Appendix A. Calculating forecast errors for potential and actual GDP.}

When it comes to GDP forecast errors our methodology is straightforward. Let the forecast made in year $t$ of a variable $Y$ for the year $t+i$.

$$
Y_{t+i}^{F, t}
$$

So for GDP in 2009, the forecast made in 2007 will be expressed as

$$
G D P_{2009}^{F, 2007}
$$

We can compare these forecasts with the actual data for GDP at a later date to compute the forecast error. In some cases when we are talking about a future date from the perspective of both years we are calculating the change in forecast between the two years.

As an example, we an calculate the forecast error for the year 2009 made in 2007 by comparing to the actual data from the 2016 vintage of the WEO as:

$$
F E_{G D P, 2009}^{2007}=\frac{G D P_{2009}-G D P_{2009}^{F, 2007}}{G D P_{2009}^{F, 2007}}
$$

The only issue we face when comparing these two GDP levels is that because of data revisions, changes in base year and also changes in national accounting rules, the forecast and the actual data might not be comparable as they might not be in the same units or follow the same national accounting criteria.

Because we are interested in revisions to growth rates, we make the two number comparable by rebasing the original WEO 2007 real GDP series and its forecasts so that the 2006 data matches the data for that year of the WEO April 2016. In other words, given that the 2006 data now coincides in both the April 2007 and the April 2016 databases, the expression above can simply be calculated as the forecast error of accumulated GDP growth from 2006 to 2009:

$$
F E_{G D P, 2009}^{2007}=\frac{G D P_{2009}^{2016}-G D P_{2006}^{2016}}{G D P_{2006}^{2016}}-\frac{G D P_{2009}^{F, 2007}-G D P_{2006}^{2007}}{G D P_{2006}^{2007}}
$$


Where

$$
G D P_{t}^{t+1}
$$

refers to the data of GDP for year $t$ as reported in the vintage for year $t+1$.

When it comes to potential output we face a more challenging task. In April 2007 when the IMF produces a number for potential output for 2006, this is not observed, it is an estimation of what they believed at that point potential was. Future values of potential output are also dependent on their views at that point in time.

Later when the crisis is in full force the IMF revises its views of potential output but it also changes its views on the level of potential output in the past. These revisions are very large and they completely change the perception of potential output levels in previous years. This means that a calculation of forecast errors of the level of potential GDP based on the accumulation of forecast errors of potential growth rates, as calculated above, would be misleading. Because the IMF has dramatically changed their views on potential output for both the current and future years by rewriting history, it would seem as if the previous path of potential output (measured in growth rates) has not changed that much. But the level has and we need to incorporate that in our estimates.

The way we do it is by ignoring these revisions and focusing on the level of potential GDP and not on its growth rates. We still need to take into account changes in national account rules or base year that might make the two numbers not fully comparable. In order to deal with these issues, we apply a correction factor to the potential output figures based on the revisions done to the latest GDP data from the perspective of the earlier vintage of the WEO being used. For example, in the calculation above for the forecast error for potential GDP in 2009 from the perspective of the April 2007 vintage, we rebase the potential output series found in the April 2007 database by the following factor:

$$
\frac{G D P_{2006}^{2016}}{G D P_{2006}^{2007}}
$$

We use 2006 as the year where the GDP data is known in April 2007 and look at the ratio of GDP in 2006 as calculated in the April 2007 and April 2016 vintages to make the potential output series comparable across the two databases. 
Once this correction is applied we can calculate the forecast error as:

$$
F E_{G D P, 2009}^{2007}=\frac{P O T_{2009}^{2016}-P O T_{2009}^{* F, 2007}}{P O T_{2009}^{* F, 2007}}
$$

Where

$$
\mathrm{POT}_{2009}^{* F, 2007}
$$

is the rebased series of the forecast of potential GDP from the April 2007 vintage using the adjustment factor. 


\section{Appendix B. Sample of Countries.}

\begin{tabular}{ll} 
Advanced & Emerging \\
\hline Australia & Algeria \\
Austria & Angola \\
Belgium & Argentina \\
Canada & Bangladesh \\
Czech Republic* & Brazil \\
Denmark & Chile \\
Estonia*,** & China \\
Finland & Colombia \\
France & Egypt \\
Germany & Ethiopia \\
Greece & Ghana \\
Hong Kong & India \\
Iceland & Indonesia \\
Ireland & Iran \\
Israel & Kazakhstan \\
Italy & Kenya \\
Japan & Malaysia \\
Korea & Mexico \\
Latvia*** & Morocco \\
Luxembourg** & Nigeria \\
Malta* & Pakistan \\
Netherlands & Philippines \\
New Zealand & Poland \\
Norway & Russia \\
Portugal & Saudi Arabia \\
Singapore & South Africa \\
Slovak Republic* & Sudan \\
Slovenia & Thailand \\
Spain & Ukrainey \\
Sweden & \\
Switzerland & \\
Taiwan & \\
United Kingdom & \\
United States & \\
\hline
\end{tabular}

* Advanced economies with missing data on potential GDP in the April 2007 WEO.

** Advanced economies with missing data on either potential GDP or Structural Budget Balances in the April 2010 WEO. 